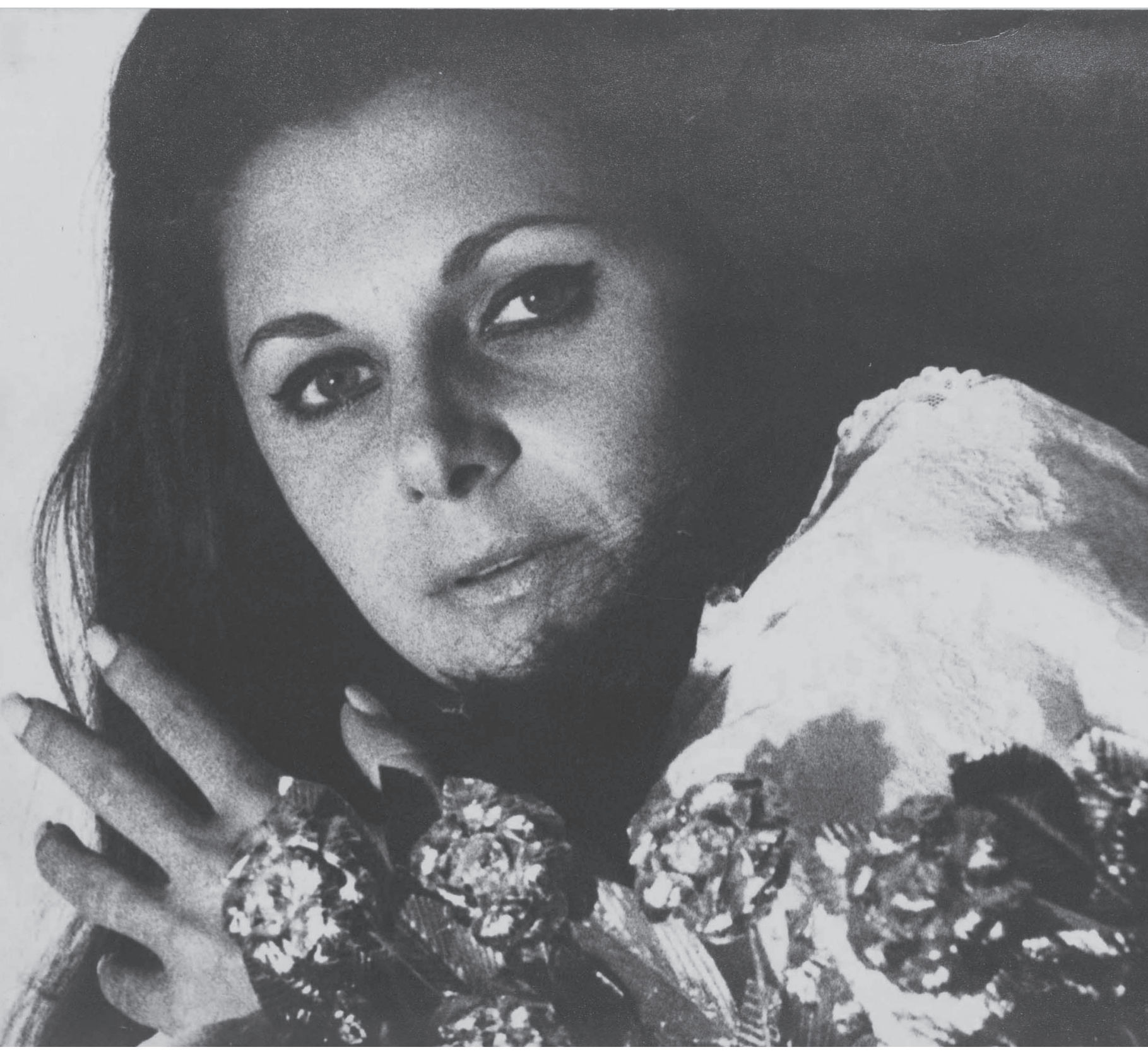




\section{Ser poeta: Lupe Cotrim, 40 anos depois}

\section{Leila V.B. Gouvêa}

palavras-chave: Lupe Cotrim; seminário; exposição; recital; Instituto de Estudos Brasileiros da Universidade de São

Paulo

keywords: Lupe Cotrim; seminar; exposition; recital; Instituto de Estudos Brasileiros of Universidade de São

Paulo
Este texto faz uma síntese dos eventos Ser poeta: Lupe Cotrim, 40 anos depois, promovidos pelo Instituto de Estudos Brasileiros da Universidade de São Paulo (IEB-USP), em março de 2010. Além de um seminário sobre obra e vida da "professora-poeta", os eventos desdobraram-se em uma exposição com peças de seu acervo, recentemente incorporado pelo IEB, e num recital, com a primeira apresentação de canções compostas por Almeida Prado sobre poemas da autora.

This paper presents a résumé of the events Being poet: Lupe Corim, 40 years afterwards, promoted by Instituto de Estudos Brasileiros of Universidade de São Paulo (IEB-USP) in March 2010. Beyond a seminar about the life and work of the teacher and poetess, the events had included an exposition of her private records' pieces, recently incorporated into the Archives of the IEB; and a recital that had presented the première of songs recently composed by Almeida Prado on some Lupe Cotrim's poems. 
1. 0 poeta César Leal enviou seu texto - também adiante publicado - do

Recife, onde reside.

As comunicações

de Carlos Felipe

Moisés, Fábio Lucas

e Telê Ancona Lopez

foram encaminhadas

à Revista do IEB, a convite de seu editor, Professor Paulo lumatti.

[Lamentavelmente, nem

todos os expositores apresentaram seus textos em tempo hábil para serem publicados].
Os textos que se seguem resultaram de um tríplice evento realizado pelo Instituto de Estudos Brasileiros da Universidade de São Paulo (IEBUSP), em 23 de março de 2010, em memória da poeta Lupe Cotrim Garaude (1933-70), que foi professora de Estética e Pensamento Filosófico nos primeiros anos desta Escola. Sob o título geral Ser poeta: Lupe Cotrim, 40 anos depois, essa rememoração desdobrou-se em um seminário em torno de obra e vida da professora-poeta; na abertura de uma exposição, com a reunião de dezenas de documentos do acervo da escritora - o qual, desde 2007, encontra-se sob custódia do IEB, mediante doação de seus filhos, o Professor Marco Giannotti e Lupe Maria Ribeiro Lima; e na apresentação de um recital, com a pré-estreia do ciclo de canções para canto e piano composto por Almeida Prado sobre poemas do quarto livro de poesia de Lupe, Cânticos da terra (1963), especialmente para essas homenagens em memória da autora, nos quarenta anos de seu prematuro desaparecimento.

O seminário sobre Lupe Cotrim, aberto pela diretora do IEB, Professora Ana Lúcia Duarte Lanna, segmentou-se em três mesas: 1. "A professora poeta”, que reuniu quatro antigos alunos de Lupe na ECA: os professores Ismail Xavier, Luís Milanesi - cujos textos são reproduzidos nas páginas seguintes - e Waldir Ferreira, talvez um dos primeiros estudantes que propuseram o nome da escritora para o Centro Acadêmico da ECA, em 1970 -, além de mim mesma, sua aluna em 1969. 2. "Uma intelectual na travessia dos anos 60", que abordou a estudante de Filosofia nos tempos da faculdade da rua Maria Antônia, além da intelectual inquieta e estudiosa atenta, sempre em sintonia com o seu tempo, contando com comunicações dos professores Fábio Lucas, Eduardo Peñuela Canizal, Anamaria Fadul e Telê Ancona Lopez; 3. E "A poesia lírica de Lupe Cotrim", com a participação dos poetas Carlos Felipe Moisés, Renata Pallottini e César Leal e do crítico Manuel da Costa Pinto ${ }^{1}$. O encontro foi encerrado pela escritora Lygia Fagundes Telles, que teceu lembranças de sua estreita amizade com Lupe Cotrim nas décadas de 1950-60, e pelo filósofo José Arthur Giannotti, professor emérito da USP, que foi casado com a poeta.

O crítico literário Manuel da Costa Pinto mencionou a presença do sublime na lírica de Lupe Cotrim, referiu-se ao período engajado de sua escrita, sobretudo em seu último livro, o triplamente premiado Poemas ao outro (1970) - escrito em resposta aos "anos de chumbo" que se anunciavam no horizonte -, e reviu algumas das "poéticas" da autora, como "Entre arma e torre", que encerra o livro Cânticos da terra, e principalmente "Visão da palavra", de sua quinta coletânea, O poeta $e$ o mundo (1964): 
A palavra é móvel, fluida, em seu corpo interpretado.

De tudo que era, mantém ainda o traçado, permanecendo contínua em seu devir.

A palavra é um rio de pedra.

Mantida em dicionário

eis que palpita

qual pássaro contido

no alcance de seu voo

- cabe à voz de um gesto libertá-la.

$[\ldots]$

A palavra é humana.

$[\ldots]$

"Visão da palavra", O poeta e o mundo.

Formando, com Hilda Hilst e a autora homenageada, o trio de jovens, belas e promissoras poetas paulistas que estrearam na década de 1950, Renata Pallottini lembrou no IEB a convivência com Lupe Cotrim, os poemas lúdicos do bestiário Cânticos da terra e releu a poesia que escreveu em memória da amiga, em 1983, quando os escritores celebraram Lupe no ano em que se completaria o seu cinquentenário de nascimento:

Todo poeta é uma flor que permanece

espada aérea e franca

contra a morte

Todo poeta é uma cor que permanece

no olhar sobrevivente

e na luz das manhãs que voltam sempre

Lupe

lume de azul

longe beleza

antena sobre o espaço

e carne quente

sílaba proferida, pesadelos

a transitoriedade que se esquece

na luta pela vida

passageira

Todo poeta é uma dor que permanece

Renata Pallottini, sem título. 
2. Todos os livros de Lupe Cotrim, inclusive as coletâneas póstumas, encontramse esgotados; atualmente, sua família planeja reeditar Obra consentida.

3. Carta de Lupe Cotrim a Carlos Drummond, 3 set. 1963 [Original Fundação Casa de Rui Barbosa, cópia IEB.] [0 diálogo epistolar entre Lupe Cotrim e Carlos Drummond é tema do artigo Algumas lições do amigo, de minha autoria. In: Revista do IEB, São Paulo: IEB, USP, Editora 34, n. 48, mar. 2009, p. 53-76].
Com uma seleção de documentos de seu acervo, a exposição Ser poeta: Lupe Cotrim, 40 anos depois - título inspirado em seu poema "O dúplice" - procurou reconstituir o itinerário intelectual e literário da autora, desde o projeto, formulado aos doze anos, de tornar-se escritora, o qual depois viria a se metamorfosear no de "ser poeta". Daí resultou a publicação de sete livros de refinada poesia lírica: Monólogos do afeto (1956), Raiz comum (1959), Entre a flor e o tempo (1961), Cânticos da terra (1962-63), O poeta e o mundo (1964), Inventos (1967) e Poemas ao outroeste, laureado com os prêmios Jabuti, Governador do Estado e o de Poesia da Fundação Cultural de Brasília. Depois da morte de Lupe, apareceu a sua Obra consentida (Brasiliense, 1973), com a seleção de poemas que a própria autora fez de seus cinco primeiros livros, mantendo os dois últimos na íntegra, por considerá-los inaugurais de uma nova dicção em sua lírica - a essa coletânea, José Arthur Giannotti acrescentou uma série de inéditos de sua última fase. Em 1984, foi ainda publicada a antologia Encontro (Coleção “Cantadas literárias”, Brasiliense), organizada por seu filho, Marco Giannotti, na época ainda adolescente ${ }^{2}$.

Em sua "procura da poesia", Lupe buscou também a Faculdade de Filosofia da USP, ainda na rua Maria Antônia, onde desenvolveu empenhados estudos com o intuito de adensar a sua "concepção do mundo”, pesquisar uma nova dicção poética e depurar sua escrita. Nesse período, também sondou a possibilidade de certa modalidade de "poesia fenomenológica", a partir das poéticas de Carlos Drummond de Andrade, João Cabral de Melo Neto e do francês Francis Ponge, o poeta da "volta às coisas", sobre o qual chegou a planejar uma tese de doutoramento em Estética, sob orientação da Professora Gilda de Mello e Souza - projeto que, com sua morte prematura, ficaria inacabado.

Lupe também cultivou o diálogo e a troca de cartas com escritores, especialmente com Carlos Drummond, o maior interlocutor epistolar de sua vida breve. Foi ao autor do Fazendeiro do ar que escreveu, contando sua decisão de, formada quando muito jovem em biblioteconomia e cultura pelo Sedes Sapientiae, voltar a estudar, em 1963:

Entrei na faculdade de Filosofia, há anos que eu a vinha namorando de longe. Minha realização como poeta só se efetivará na medida da minha concepção do mundo - quero dar [à minha poesia] a objetividade de que necessita. [E comunicava ao amigo:] Você nem imagina como é admirado e querido entre os professores (todos jovens, cultos, inteligentes, um Brasil de causar a maior esperança). Sua poesia é sentida e compreendida lá no fundo ${ }^{3}$. 
4. Carta de Carlos Drummond a Lupe Cotrim, 8 set. 1965 [Original Fundação Casa de Rui Barbosa, cópia IEB].

5. Carta de Carlos Drummond a Lupe Cotrim, 22 abr. 1963, Arquivo IEB.
Drummond foi grande incentivador dos estudos da jovem poeta, empenhada em "aumentar o equipamento cultural que tantos intelectuais desdenham, por preguiça”, escreveu ${ }^{4}$. E, mesmo em sua prática epistolar "pouco expansiva", sempre a estimulou no caminho da poesia. Como quando da publicação de seu quarto livro, um bestiário publicado por Massao Ohno, com ilustrações de Aldemir Martins:

Lupe, amiga querida: $\mathrm{O}$ mais faltoso e omisso de seus amigos aqui está para agradecer Cânticos da terra, livro que não é belo só na aparência e por artes do Aldemir Martins, mas também, e fundamentalmente, pela poesia "Entre arma e torre", de que nele você dá exemplos tão ealizados e completos. Sou um velho apaixonado do mistério dos animais, Lupe, e encontro com emoção em seus poemas esse poder de ir até o mais delicado deles, essa essência de vida e significado que a natureza não oferece cabalmente senão através da intuição poética. Você abriu uma avenida larga em sua poesia, e nela cabem as mais intensas formas de existir com o animal e no mundo. Obrigado, Lupe, e um abraço maior pela lindeza de seu livro 5 .

Valerá lembrar o poema "Entre arma e torre", tão bem avaliado por Drummond, um dos muitos em que Lupe Cotrim alude à busca de uma dicção autoral, independente tanto do esteticismo da "geração 45" quanto das vanguardas que pululavam na época, especialmente a poesia concreta, e também de uma sorte de "poesia social” panfletária:

Não a torre de marfim cristalizada em cerca de mim a mim.

- Monologar amores

o corpo narciso no riso e nas dores.

Não fratura na palavra na forma indecisa que joga e não fala.

- Passageiros reflexos de imagens carentes morrendo sem eco.

Não procura da mensagem a ser arma guerreira no gesto da coragem.

- Verdade direta que pronto incendeia e ao povo desperta. 
Antes

olhar o homem para o homem

dentro na natureza,

linguagem secreta no eterno

presente do que vale.

E permanece.

Assim ser poeta.

"Entre arma e torre", Cânticos da terra (1963).

Nesse poema, escrito a meio de um caminho poético de breve duração, Lupe reafirma o viés humanista, latente desde os seus primeiros versos, o qual passaria pelo crivo da reflexão crítica em seus estudos de Filosofia - ao fim dos quais ingressou como docente colaboradora, em 1967, na atual Escola de Comunicações e Artes.

A mostra no IEB ainda lembrou a passagem meteórica, porém marcante, de Lupe Cotrim como professora de Estética nos primeiros anos da atual ECA, período em que combinou a escrita poética com a produção ensaística. Seus estudos sobre Lukács e Rousseau foram publicados nos dois primeiros números da então Revista da Escola de Comunicações Culturais, e outros de seus artigos saíram nas páginas do

6. Considerações sobre a oposição: narrar ou descrever. Revista da

Escola de Comunicações Culturais. São Paulo: ECC-USP, Universidade de São Paulo, n. 1, 1967, p. 121-129; Rousseau 0 ofício do imaginário. Revista da Escola de Comunicações Culturais, São Paulo: ECC-USP, Universidade de São Paulo, n. 2, 1968, p. 93-104 [No Suplemento Literário de 0 Estado de S. Paulo, saíram: A mundanidade da Bienal, 23 dez. 1967; e dois artigos em que polemizava com Décio

Pignatari acerca da "era de comunicações de massa" e McLuhan: Arte e alienação-I, 21 set. 1968, e Arte e alienaçãoII, 5 out. 1968]. legendário Suplemento Literário de O Estado de S. Paulo ${ }^{6}$.

O esquema manuscrito de seu curso e as aulas, redigidas uma a uma, na melhor tradição acadêmica, também se encontram entre seus papéis, no IEB. Estudiosa precoce da psicanálise, do feminismo ensaístico de Simone de Beauvoir, tão logo por aqui aportou em 1960, a leitora crítica e voraz de literatura, de filósofos e cientistas sociais, como Michel Foucault, Marx, Lévi-Strauss, Heidegger, Merleau-Ponty, entre tantos outros, costumava recomendar a seus atarantados alunos: "ler oitenta páginas por dia". Seja como for, terá conseguido levar aos brios de aprofundadas leituras muitos daqueles jovens. "Foi Lupe quem me ensinou a ler - pois, em sua disciplina, tínhamos de ler”, reconheceu o professor Waldir Ferreira, em comunicação oral no seminário no IEB. De resto, são copiosas as suas anotações e fichas de leituras guardadas no Fundo Lupe Cotrim Garaude (FLCG) no IEB em meio a manuscritos de poemas e de contos, da única peça de teatro que escreveu e que deixaria inacabada ("Amanhã seria diferente"), a fotografias, cartas e outros documentos de correspondência, além de resenhas e artigos de imprensa com a recepção crítica a sua obra e registro de sua marcante presença na cena literária do país nas décadas de 1950-6077. 
7. Os verbetes correspondentes aos 1.108 documentos do FLCG já estão disponíveis para consulta no Catálogo eletrônico do IEB: 〈www.ieb.usp.br〉, link acervo on-line.

8. In: Rachel Bertol, Uma poeta interrompida. Eu\& Fim de Semana, Valor, São Paulo, 26-28 mar. 2010, p. 24-25; e depoimento inédito.

[Essas composições de Almeida Prado contaram com apoio da FAPESP.]

9. Ver depoimento de depoimento de Dulce Simonsen, in: Lupe Cotrim, Simpósios em Comunicações e Artes. São Paulo, ECA-USP, n. 7, 1990, p. 36-40.
A terceira face em que se desdobraram os eventos Ser poeta: Lupe Cotrim, 40 anos depois, no IEB, consistiu no concerto com três do ciclo de seis canções compostas por Almeida Prado sobre poemas de Cânticos da terra. Convirá transcrever excertos de dois depoimentos do compositor sobre esse trabalho em torno da poesia de Lupe:

São poemas lindíssimos. Fiquei encantado com seu estilo, que é muito pessoal, e não lembra o de nenhuma outra poeta brasileira. O texto me inspirou facilmente. [Sua poesia é] leve, transparente e colorida. [...] Ao ler os poemas, a música foi se aproximando lentamente e tomando corpo através das palavras. Dentre os onze poemas sobre bichos, escolhi seis: aqueles em torno da gaivota, do pavão, da aranha, da formiga, da borboleta e do cavalo. Cada um deles foi [por mim] vestido de diferentes texturas sonoras, criando uma espécie de cenário, onde o barítono traduz o texto, seja melodicamente, em recitativo operístico e também falado, à maneira do melodrama romântico. [...] Creio que chegou o tempo de Lupe ${ }^{8}$.

Será lícito imaginar o quanto essa recriação musical de alguns de seus poemas teria alegrado a poeta, quarenta anos depois de seu "encantamento". Afinal, melômana declarada, na década de 1950 Lupe estudou canto lírico por vários anos, tendo chegado a pensar em se profissionalizar como soprano. E mais de uma vez lamentou nunca ter podido ouvir alguma transcriação musical sobre seus versos ${ }^{9}$.

O que valerá como lembrete aos professores e estudantes de composição desta Escola. Com a licença de uma sugestão: musiquem textos da série "Entreato de amor", do livro Inventos (1967), extraordinário poema para vozes, em parte, talvez, inspirado em mitos como o de Tristão e Isolda, com o diálogo lírico entre dois amantes. Ou algumas de suas mais fortes poesias de crítica social do póstumo Poemas ao outro.

Leila V.B. Gouvêa foi pesquisadora em pós-doutorado no IEB-USP, onde, como bolsista da FAPESP, organizou e catalogou o acervo de Lupe Cotrim Garaude e pesquisou obra e vida da autora; dessa pesquisa, resultou o estudo Estrela breve, uma biografia literária de Lupe Cotrim, a ser publicado. Coordenou os eventos Ser poeta: Lupe Cotrim, 40 anos depois no IEB, de cuja exposição foi curadora, em parceria com a Professora Yêdda Dias Lima. 